\title{
Innovaciones democráticas desde la perspectiva de sus participantes. Una aproximación al ajuste social percibido
}

\author{
Democratic innovations from the perspective of its participants. An \\ approach to perceived social adjustment
}

\section{Patricia Mariel Sorribas \\ Mariana Carla Gutierrez}

\section{Resumen}

El artículo recoge críticas a la institucionalidad participativa de distintas latitudes reconociendo dimensiones relevantes para luego establecer, desde la perspectiva de los/as participantes, si se asocian a las experiencias implementadas en Córdoba (Argentina). Analizamos la valoración de actores intervinientes en procesos participativos en torno a políticas culturales y en órganos de participación. En base a evidencia producida mediante encuestas, entrevistas y análisis de documentos concluímos que las experiencias cordobesas de participación ciudadana registran indicadores de desajuste social, debilitando la aceptación de la institucionalidad asociada a una concepción participativa de la democracia local. Estos resultados pueden corresponderse con una interpretación del contexto político como no cambiante a pesar de la apertura e innovación institucional. En el campo de las políticas culturales, el desajuste social es parcial dada la percepción de que esos procesos refuerzan la autodeterminación y la justicia, redundando en una mayor aceptación institucional. Sin embargo, la democratización en la toma de decisiones de políticas culturales resultó desigualmente distribuida.

\section{Palabras chaves}

Participación Ciudadana; Democracia Participativa; Aceptación Institucional; Ajuste Social Percibido.

\begin{abstract}
The article collects criticisms of the participatory institutionality of different latitudes, recognizing relevant dimensions; then from the perspective of the participants, it establishes whether they are associated with the experiences implemented in Córdoba (Argentina). We analyze the assessment of actors involved in participatory processes around cultural policies and in participation bodies. Based on the evidence produced by surveys, interviews, and analysis of documents, we conclude that the Cordoba experiences of citizen participation record indicators of social imbalance; which weakens the acceptance of the institutions associated with a participatory conception of local democracy. These results may correspond to an interpretation of the political context as unchanging despite institutional openness and innovation. In the field of cultural policies, social imbalance is partial given the perception that these processes reinforce selfdetermination, resulting in greater institutional acceptance. However, democratization in cultural policy decision-making was unevenly distributed.
\end{abstract}

\section{Keywords}

Citizen Participation; Participatory Democracy; Institutional Acceptance; Perceived Social Adjustment. 


\section{Introducción}

En las sociedades "avanzadas", el alcance de las actividades y responsabilidades del gobierno se amplía progresivamente, afectando a prácticamente todos los aspectos de la vida social (VAN DETH, 2001). El Estado interviene de alguna manera en todo tipo de relaciones (salud, educación, producción, sexualidad), ya sean del ámbito público o del privado (consumo de sustancias) y a nivel de la población. A la par, desde comienzos del siglo XXI el dominio y el repertorio de la participación política se expanden considerablemente. Dentro de sistemas democráticos, su análisis se torna socialmente relevante ya que constituye un indicador clave sobre la performance, la vitalidad y la estabilidad del sistema, tanto si se considera su cuantificación como su calidad. A su vez, las "diversas versiones sobre la democracia y el alcance que debe tener la participación de los ciudadanos, permite la existencia de diferentes interpretaciones de la participación" (SABUCEDO, 1996, p. 85).

Al considerar concepciones representativas de la democracia, en gobiernos que pretenden constituirse en "abiertos, la idea de openness parece dar origen a una nueva panacea para promover la participación ciudadana en los asuntos públicos, mejorar la gestión gubernamental y producir una transformación estatal que destaque la centralidad del ciudadano, reforzando aspectos deliberativos y participativos de la democracia. En este marco la participación ciudadana adquiere otro sentido (OSZLAK y KAUFMAN, 2014). De hecho se concibe al Gobierno Abierto (GA) como aquél que posibilita "instituir nuevas formas de participación y empoderamiento ciudadano conducentes a una democracia deliberativa” (SÁNCHEZ GONZÁLEZ, 2020, p. 15). A su vez, Ińaki Akerreta (2014, citado en OSZLAK, 2014, p. 38), sostiene que "ya no solo estamos hablando de reforma de la burocracia sino que estamos hablando de la reforma de la democracia representativa y su paso a la democracia participativa". Así las reformas que requiere un GA pleno suponen acciones que afectan el diseño y el funcionamiento de las instituciones en al menos dos sentidos: cambios en la organización del poder (dimensión política) y en los organismos y servicios públicos que diseñan y ejecutan políticas (dimensión administrativa) (RAMÍREZ ALUJAS y DASSEN, 2012).

A su vez, los gobiernos abiertos deberían adoptar decisiones tendientes a ampliar la oferta de información disponible para la ciudadanía, habiéndola consultado previamente para así asegurarse la pertinencia o utilidad de su publicación (OSZLAK, 2014). Esto es así ya que la apertura hacia este rol protagónico de la ciudadanía responsable de la cogestión de políticas públicas- implica que las administraciones 
públicas se beneficien de sus conocimientos, recursos, ideas y experiencias. Es frecuente dar con estudios que registran que la gran mayoría de la ciudadanía conoce poco acerca del mundo político (BARABAS, 2004); lo cual ha sido evidenciado también en Córdoba (Argentina) (SORRIBAS, 2017) y que las preferencias (partidarias) de estos ciudadanos podrían modificarse si estuvieran más informados. Estos resultados cuestionan los propios fundamentos de la democracia.

Es concebible que modalidades participativas no electorales incrementen el conocimiento, por medio de las actividades deliberativas. Es decir, la deliberación podría superar el déficit informacional dado que ningún individuo puede, por sí solo, poseer todos los datos relevantes para tomar una decisión (MANIN, STEIN y MANSBRIDGE, 1987). Estas prácticas posibilitarían inclusive que la ciudadanía cumpla un papel importante como co-legisladora.

En Latinoamérica, en el marco de versiones más participativas de la democracia se implementaron nuevos diseños institucionales que contemplan la intervención de la ciudadanía, individual o colectivamente, en procesos de toma de decisión y que contemplan procesos de consulta, deliberación y negociación. A diferencia de los mecanismos de la democracia directa (más taxativos: una vez efectuada la votación, no admiten soluciones intermedias), estos diseños presuponen un resultado abierto (LISSIDINI, 2011).

En esta región, desde la década de 1990 la incorporación de la sociedad civil como mecanismo para extender la ciudadanía se difunde bajo el tópico de la participación ciudadana. Esta noción puede diferenciarse en dos grandes ámbitos: 1) órganos de participación: "espacios estables de participación que, con una composición determinada -habitualmente en forma de consejo-, actúan como espacios consultivos de forma permanente sobre las políticas desarrolladas en un determinado ámbito temático o territorial" (PARÉS I FRANZI, 2009, p. 23); y 2) procesos participativos: "formas de participación institucional que se desarrollan durante un determinado periodo de tiempo para implicar a la ciudadanía en la elaboración de un proyecto, un plan o una política concreta" (PARÉS I FRANZI, 2009, p. 23).

La participación ciudadana principalmente en su versión asociada a los órganos ha sido apropiada y estimulada desde el propio Estado creando y promoviendo "formas diferenciadas de incorporación de los ciudadanos y asociaciones de la sociedad civil en las deliberaciones públicas" (AVRITZER, 2008, p. 3). En esa apropiación es posible reconocer tanto la concreción de "proyectos participativos construidos en torno a la 
profundización y expansión de la democracia participativa, como la permanencia de la lógica neoliberal y la reconfiguración del poder estatal por medio de la sociedad" (SORRIBAS y GARAY REYNA, 2014, p. 40). En ese sentido Dagnino (2018) analiza el régimen democrático brasilero extrayendo conclusiones extrapolables a la región Latinoamericana y señala que entre el proyecto neoliberal y el proyecto democráticoparticipativo existe una "confluencia perversa" entre referencias comunes a ambos, pero que remiten a significados diferentes. Esto es así, dado que "avanzando en direcciones opuestas y hasta antagónicas, ambos proyectos requieren una sociedad civil activa y propositiva" (DAGNINO, 2018, p. 681).

Ante esa confluencia se vienen implementando estas innovaciones, con variados desempeños. A principios de este siglo, Peruzzotti y Smulovitz (2002) sostenían que el funcionamiento de esta institucionalidad permitió evidenciar que habilitó tanto acciones de veto como de control ciudadano que fueron significativas en Latinoamericana. Otros antecedentes también resaltan algunos resultados positivos obtenidos en relación con diversas políticas públicas urbanas mediante procesos de incidencia política (AVRITZER, 2011; ISUNZA VERA y GURZA LAVALLE, 2012). Parte de esa valoración positiva se reconoce en el desembarco y arraigo europeo de estas instituciones surgidas en el sur del globo, lo que fue significado como el retorno de las carabelas (ALLEGRETTI y HERZBERG, 2004; SINTOMER, HERZBERG y RÖCKE, 2008). Surgimiento entendido como un "replanteamiento virtuoso de los modelos de gestión territorial a menudo tomados de países del viejo continente, tanto durante como después de los períodos de colonización" (ALLEGRETTI y HERZBERG, 2004, p. 1).

De todos modos, en nuestro trabajo nos interesa revisar las voces críticas de distintas latitudes sobre esta institucionalidad para establecer qué dimensiones y estándares relevantes las sustentan y luego producir evidencia -desde la perspectiva de los/as participantes- sobre experiencias similares arraigadas en la provincia de Córdoba (Argentina) tratando de reconocer en ellas cuáles críticas les caben.

\section{La participación ciudadana y sus limitaciones}

Al revisar el vínculo entre democracia representativa y participativa, algunos trabajos evidencian que la actuación de los institutos participativos está permeada por las dinámicas de los procesos políticos propios de la democracia representativa. Romão (2016) registra esta imbricación en su estudio sobre el funcionamiento del Presupuesto Participativo (PP) en municipios brasileños, concluyendo que los consejeros están 
altamente vinculados al oficialismo, cuanto más centralidad tenga el PP para la administración local. En palabras del autor, "cuanto más alto es el estatus político del PP en la Administración Local, su consejo es más disputado y ocupado por representantes afiliados al partido político en el poder. Es decir, se produce un conflicto donde los grupos más organizados dirigen sus estrategias de ocupación del espacio político hacia el PP” (ROMÃO, 2016, p. 69), ampliando así la participación sólo hacia adentro de la sociedad política (ROMÃO, 2011).

Algo similar sucede en Madrid, según Iglesias Alonso (2009, p. 60) "la participación ciudadana a nivel local está monopolizada por grupos y asociaciones bien organizados”. Allí las Juntas de Vecinos estaban en su mayoría colonizadas por los partidos políticos y controladas por el que tenía la mayoría absoluta en el Ayuntamiento. Así, los Consejos Vecinales reprodujeron la estructura de división política del Ayuntamiento dominado por el partido político que ejercía el gobierno local.

En Córdoba (Argentina) quienes se vinculan con las instituciones participativas locales tienden a contar con participación previa y/o simultánea en partidos políticos y/o Centros Vecinales (institución enmarcada en una concepción representativa del territorio sub-municipal: barrio) (SORRIBAS, EBERHARDT y GUTIÉRREZ, 2016). Y las convocatorias se realizan por "afinidad político-partidaria o reproducen, como en el caso de las Audiencias, las invitaciones con los antiguos participantes y su red de relaciones" (ECHAVARRÍA y ROMANUTTI, 2014, p. 47).

Y no solo los partidos políticos permean esta institucionalidad. Para Sintomer (2018) la gobernanza real implica que algunos actores colectivos, muy a menudo privados o no sujetos al control popular, tienen una participación desproporcionada en el proceso de toma de decisiones ${ }^{1}$. Por ello sostiene que a nivel macro la estructura de poder está muy lejos de la influencia de los entornos deliberativos y que cualquier dispositivo deliberativo participativo podría ser instrumental en la legitimación estratégica de la dominación política si no se vincula con un cambio más amplio.

Complementariamente Santos, Batel y Gonçalves (2018) sostienen que esta institucionalización de la participación permitió, especialmente en los últimos años, el desarrollo de una retórica institucional, por parte de los decisores y algunas fuerzas políticas: que los procesos de toma de decisiones ya se llevan a cabo con la participación

\footnotetext{
${ }^{1}$ En Córdoba se evidencia en las decisiones urbanísticas, los convenios implican una profunda discrecionalidad del Ejecutivo municipal que promueve la inversión privada con la única lógica de la acumulación y especulación (VALENCIA, 2019).
} 
de la ciudadanía, si es que ella quiere participar. Este discurso, parece garantizar la participación de/como ciudadanos pero expresa una concepción tokenista del involucramiento, reproduciendo las tradicionales relaciones de poder entre los sistemas técnico-políticos y los laicos, generando una participación light y evitando a menudo la discusión y el análisis del papel concomitante de factores estructurales, ideológicos y contextuales-relacionales. Inclusive instancias que promueven oportunidades de participación/decisión, como el PP, parecen diseñadas desde concepciones que asumen que la ciudadanía necesita orientación para tomar la mejor decisión (SANTO et al., 2018), lo que puede ser leído como soft-paternalismo (COLANDER y QUI LIN CHONG, 2009). Evidencia similar ha sido reportada en Córdoba para las Juntas de Participación Vecinal (JPV), donde se observa frecuentemente el uso de la información como recurso de poder, tanto por autoridades como por algunos vecinos participantes, entronizando al saber técnico sustentado por unos pocos (ECHAVARRÍA y ROMANUTTI , 2014).

Adicionalmente desde el análisis de las representaciones que los sistemas técnico-políticos sostienen sobre la participación ciudadana se han identificado varias estrategias retóricas utilizadas por ellos como instrumentales en la negociación y resistencia al cambio: a) la distinción entre la norma y la práctica de la participación ("sí, la participación es importante, pero en este caso somos nosotros los que sabemos"); b) la distinción nosotros versus ellos para acentuar las diferencias entre grupos; y c) el uso estratégico del ethos (capacidad de influencia del hablante), pathos (proximidad y emoción que puede desencadenar el discurso producido) y logos (demostración de la racionalidad del propio argumento discursivo) (SANTOS et al., 2018).

Esto demuestra que los sistemas técnico-políticos que tienen el poder de definir quiénes, cómo y cuándo participan, mediante estas estrategias refuerzan la tendencia a no valorar las experiencias del público en general, impidiendo el aporte de otros conocimientos; lo que finalmente dificulta la generación de epistemologías alternativas (SANTOS et al., 2018). Este poder definitorio en Córdoba está concentrado (ECHAVARRÍA y ROMANUTTI, 2014) y se agudizó durante la situación de pandemia (SORRIBAS, GUTIERREZ, GARAY REYNA y MALDONADO, en prensa).

Reafirmando los hallazgos ya reportados, Gomes Dau, Prezotti Palassi y Zorzal e Silva (2019) sostienen que la vasta literatura sobre los Consejos de Gestión (salud, asistencia social, educación, etc.) ya ha diagnosticado y enumerado varios factores que intervienen en la relación entre los representantes de la sociedad civil y los del gobierno. 
Entre ellos, destacan los siguientes: problemas derivados de la escasa formación y tradición participativa, escasa infraestructura física; uso del Consejo para maniobras de legitimación política; capacitación insuficiente o exigua de los directores; empoderamiento débil, y poca claridad de los actores civiles sobre qué se entiende por participación, "a menudo vista como sinónimo de presencia física" (GOMES DAU, et al., 2019, p. 201). Algo similar observó Warren (2014) respecto de los usos dominantes de las innovaciones democráticas -inclusive los mini-públicos- ya que parecen ocurrir dentro de los sistemas administrativos, impulsados por burócratas que descubren que la democracia electoral no les proporciona la legitimidad que necesitan para hacer su trabajo

Por otra parte, Iglesias Alonso (2009) concluye que la mayoría de los nuevos experimentos en innovación democrática terminan en fracaso porque producen una reducción en la esfera política y porque tales experiencias se distribuyen de manera desigual mejorando la calidad democrática sólo en algunos lugares.

Por su parte, Fishkin (2018, p. 209) nos aporta una dimensión más de esta institucionalidad que resulta vital: "no es que los ciudadanos sean incompetentes, es que las instituciones no son habilitadoras. No son lo suficientemente fáciles de usar como para que la mayoría de los ciudadanos piensen que vale la pena el esfuerzo y la recompensa en términos de impacto. Es como si estuviéramos conectándolos con un sistema operativo incorrecto".

En su versión asociada a los procesos participativos, la participación ciudadana puede desplegarse en vinculación con legisladores, reparticiones estatales locales y funcionarios para definir un programa concreto o una política sectorial. Al respecto es relevante que -ante la valorización de las esferas subnacionales y municipales en un contexto de descentralización ${ }^{2}$-, los gobiernos locales también asumieron mayores responsabilidades en el campo cultural (TASAT, 2009), donde el protagonismo de los niveles nacional y provincial era indiscutido. En este campo específico el uso de las categorías acceso y participación constituyen indicadores de democracia cultural y ciudadanía cultural (BAYARDO, 2008; CHAUI, 2013; MENDES CALADO, 2015; MONTALI, 2020; VICH, 2014). Se asume que la participación no puede alcanzarse

\footnotetext{
${ }^{2}$ En Argentina el Consenso de Washington implicó una descentralización en pos del corrimiento del Estado nacional de su rol impulsor del desarrollo. Como corolario los gobiernos locales emergían a una mayoría de edad" (MENDES CALADO, 2012, p. 130) asumiendo mayores responsabilidades en sus procesos de desarrollo.
} 
sin el acceso, pero el proceso de democratización cultural se perfecciona sólo si a la ampliación de la participación en la fruición y producción cultural se le adiciona la participación en la toma de decisiones.

Mendes Calado (2012) concluye que las carteras de cultura locales de municipios de la provincia de Buenos Aires participan del discurso que reconoce a la cultura tanto en su registro antropológico como estético y "de ideas tales como el respeto por la diversidad, la democratización del acceso a los servicios culturales, el aliento de la participación universal en el desarrollo cultural, los derechos culturales, etc.” (MENDES CALADO, 2012, p. 141). Sin embargo, en cuanto al carácter participativo de las políticas implementadas, cabe señalar que el discurso que prima es el de la democratización en el acceso a los bienes culturales más que de democratización en el diseño de las políticas. Al respecto, Mercadal (2020) al analizar las políticas culturales locales de Villa María (Argentina), registra una predominante tendencia difusionista para fortalecer el acceso a bienes y servicios culturales. Y señala una fuerte tendencia a la descentralización, entendida como traslado de propuestas o actividades generadas desde la gestión cultural municipal a diferentes espacios de la ciudad.

Por su parte, Gutiérrez (2019) resalta el componente participacionista presente en las acciones y discursos relativos a políticas culturales de base comunitaria (redes y referentes del Movimiento Cultura Viva Comunitaria) por parte de actores que participaron en procesos de incidencia nacional (Argentina) y local relacionados a ese ámbito. Componente que fue reconocido a nivel nacional formalmente (Resolución 190/2016) asumiendo como eje prioritario el empoderamiento ciudadano y la visibilización del sector. Frente a la "paradoja de escala" (GUTIÉRREZ y SORRIBAS, 2020) la localización se presenta como una posibilidad de afrontar las debilidades de los Estados nacionales que diseñan políticas de Puntos de Cultura y de dar lugar/participación a ámbitos estatales municipales o sub-municipales mejor articulados con actores colectivos e institucionales presentes en el territorio. Sin embargo, nuevamente y al igual que lo evidenciado respecto de los órganos participativos, son los grupos más organizados o articulados en red, con mayor interés/activismo y que tienen contacto con funcionarios de las gestiones culturales municipales quienes logran efectivamente participar en el diseño de programas culturales o en la legislación. En Córdoba (Argentina), el Programa Cultura de Barrio, la Promoción de la Cultura Viva Comunitaria (Ordenanza 12957/2019) y los Festejos comunitarios de Carnaval (Ordenanza 12500/2015) no surgieron desde la institucionalidad, sino por iniciativa de la acción colectiva, aunque no puede menospreciarse la importancia de la 
"receptividad" de funcionarios de la cartera cultural municipal y la estructura de oportunidades políticas (LEIRAS, 2007). Dichos procesos políticos participativos a su vez dan lugar a la implementación de órganos participativos. En tal sentido, para la Cultura Viva Comunitaria se contempla en el texto de la Ordenanza 12957 de 2019, una instancia de participación institucionalizada (Consejo Municipal de Cultura Comunitaria). Sin embargo, no está en funcionamiento dado que no se reglamentó aún la cantidad y renovación de integrantes para que exista efectiva participación de las organizaciones culturales comunitarias (SORRIBAS et al., en prensa).

En nuestro trabajo, tanto para los órganos de participación como para los procesos participativos interesa considerar una dimensión menos abordada y que considera la perspectiva de los actores: el ajuste social o qué tan bien las instituciones se alinean con las expectativas humanas y los patrones de comportamiento (Cfr. DECARO y STOKES, 2013). Recurrir al concepto aceptación institucional -es decir, cuánto los individuos respaldan a un sistema de gobierno- como un indicador de ajuste social, permite definir, diagnosticar y mejorar deliberadamente el ajuste social de los programas participativos. De acuerdo con DeCaro y Stokes (2013) cuando la participación pública en la toma de decisiones satisface la necesidad psicológica inherente de las personas de justicia procesal y autodeterminación, tenderán a percibir una institución como justa y que respalda su autonomía, promoviendo así su aceptación. Ésta indica si ha surgido un buen ajuste social y motiva a la ciudadanía local a participar más plenamente en el diseño e implementación para, a su vez, mejorar la institucionalidad. La aceptación institucional refiere a la medida en que las personas respaldan un conjunto de derechos, reglas y procedimientos de toma de decisiones y cuánto se alinean con sus metas y deseos (DECARO y STOKES, 2013); es parte del proceso de desarrollo mediante el cual los individuos adoptan las normas sociales y las instituciones de su sociedad incorporándolas a su propia identidad.

En esta misma línea podemos retomar los planteos de Carlos (2015, p. 88) para quien estas instituciones deben ser "[...] percibidas y aprehendidas por actores colectivos como oportunidades para la realización de políticas de su interés", pues estos canales, en la práctica, están interpenetrados por referentes culturales que involucran "interpretación cognitiva y cultural sobre cambios en el contexto político, que necesitan ser percibidos y procesados por los actores como incentivos para su acción colectiva” (CARLOS, 2015, p. 88). Esta institucionalidad también representa limitaciones para la acción produciendo restricciones y efectos organizacionales sobre los patrones de 
acción colectiva. Gomes Dau et al. (2019) se alinean con este enfoque al aportar evidencia sobre percepciones y creencias de los representantes por la sociedad civil en el marco de los Consejos de Gestión. Ellos reconocieron que los sentimientos de colectividad son muy claros entre los concejales, que perciben -en general- el esfuerzo colectivo en la acción de los consejeros junto a minoritarios comportamientos individualistas de algunos representantes. A su vez, revelan un descrédito en relación con la autonomía otorgada al Consejo para actuar frente al gobierno (en sus tres niveles) e incidir en las políticas de asistencia social.

En función de esta dimensión analítica, realizamos una aproximación descriptiva al ajuste social considerando las perspectivas de quienes se han vinculado tanto con órganos como con procesos participativos. Perspectivas que luego son puestas en diálogo con las dimensiones de análisis presentadas y con estándares que permiten la valoración sobre la democratización real que pueden estar propiciando. Respecto de los órganos participativos se procedió a un estudio por encuesta que permitió un análisis comparativo entre Córdoba y Villa María, ciudades que implementan de modo similar el PP y que registran atribuciones similares entre las JPV (Córdoba) y los Consejos Barriales (CB) (Villa María). Esto permite contribuir a la producción de conocimiento a nivel subnacional de estas innovaciones institucionales en Argentina. El mayor desajuste evidenciado en Córdoba puede obedecer al reforzamiento de actores vinculados a partidos políticos, dinámicas electorales o a la gestión municipal que ha sido más marcado en Villa María debido al vínculo laboral de muchos de los/as participantes.

Respecto del proceso participativo se aborda el caso de la política cultural local en Córdoba mediante un enfoque cualitativo de fuentes primarias y secundarias. Respecto del momento más reciente de dicho proceso se evidencia una percepción de desajuste ya que no se cumple con la expectativa de que se garantice una participación que sea realmente representativa del sector.

\section{Los órganos de participación: Presupuesto Participativo (PP), Juntas de Participación Vecinal (JPV) y Consejos Barriales (CB)}

En Córdoba, la Carta Orgánica (1995) incorpora institutos de democracia semidirecta y una visión descentralizada del municipio. Para ello se crearon los Centros de Participación Comunal (CPC), el Consejo Económico Social y las JPV. Éstas otorgan un papel central a los Centros Vecinales (CV) como canales participativos para plantear demandas e integran la implementación del PP. Las JPV son un instituto 
público municipal de gestión asociada y articulada entre CPC, Centros y Comisiones Vecinales, clubes, bibliotecas, centros de jubilados, escuelas, comedores, iglesias y otras entidades como las OSCs, cooperadoras y otras instituciones barriales. Poseen 3 instancias de participación: (1) Asamblea, (2) Mesa Coordinadora y (3) Comisiones Temáticas.

En Villa María la Secretaría de Gobierno y Descentralización Territorial tiene a su cargo la descentralización municipal -desconcentrar servicios y competencias- hacia los ámbitos de Gestión municipal (Centros de Gestión Descentralizados) ubicados en distintas sectores de la ciudad para lograr una mayor proximidad entre las decisiones políticas y administrativas y los intereses y demandas de la comunidad. Así se diseñan y planifican de manera participativa Planes Estratégicos Barriales, PP anuales y/o trienales y Foros Ciudadanos dentro de los que se delimitan los $\mathrm{CB}$, ámbitos de diálogo e intercambio de propuestas creados para que los vecinos diagnostiquen y proyecten planificadamente las prioridades de cada sector; están integrados por las instituciones de cada uno de los barrios que integran cada MUNICERCA.

Para analizar las perspectivas valorativas de los participantes se construyó un instrumento a partir de datos producidos en el marco del encuentro ¿Qué pasa con la participación vecinal en Córdoba? organizado por el Grupo de Democracia Participativa de la Red Ciudadana Nuestra Córdoba durante 2013. En ese marco se retomaron y actualizaron los nudos críticos diagnosticados en un encuentro similar realizado durante 2011. Así se establecieron problemáticas que se mantenían en el tiempo y otras nuevas. Se realizó una sistematización del contenido producido en los talleres. A partir de estos insumos y mediante rondas de consultas a expertos (entre ellos participantes activos en JPV y PP) y propuestas sucesivas de selección y redacción, se diseńó una escala tipo Likert con cinco opciones de respuesta ( $1=$ totalmente en desacuerdo a 5=totalmente de acuerdo) y 13 ítems (por ejemplo: "Los funcionarios del área Participación Ciudadana no duran mucho en sus cargos, afectando la gestión") priorizando la mayor validez ecológica posible de las frases. La recolección de datos se realizó entre mediados de 2015 y mediados de 2017 por etapas que alternaban ambas ciudades y en el marco de un estudio por encuesta más amplio. 
154 | Patricia Mariel Sorribas e Mariana Carla Gutierrez

Tabla 1 - Perspectiva de la ciudadanía de Córdoba sobre JPV, PP y CV: porcentajes $(\mathrm{N}=128)$

\begin{tabular}{|c|c|c|c|c|c|c|}
\hline & Items & $\begin{array}{l}\text { Totalmente } \\
\text { en } \\
\text { desacuerdo }\end{array}$ & $\begin{array}{c}\text { Algo en } \\
\text { desacuerdo }\end{array}$ & $\begin{array}{c}\mathrm{Ni} \text { de } \\
\text { acuerdo ni } \\
\text { en } \\
\text { desacuerdo }\end{array}$ & $\begin{array}{l}\text { Algo de } \\
\text { acuerdo }\end{array}$ & $\begin{array}{l}\text { Totalmente } \\
\text { de acuerdo }\end{array}$ \\
\hline & $\begin{array}{l}\text { 1. Para el PP el que } \\
\text { lleva más gente, }\end{array}$ & \multirow[b]{2}{*}{27} & \multirow[b]{2}{*}{4,9} & \multirow[b]{2}{*}{12,3} & 21,3 & 34,4 \\
\hline & $\begin{array}{l}\text { recibe más recursos. } \\
\text { Eso lo desvirtúa }\end{array}$ & & & & \multicolumn{2}{|c|}{$56 \%$} \\
\hline & 8. $\quad$ La $\quad$ Mesa & \multirow[b]{2}{*}{27} & \multirow[b]{2}{*}{4,8} & \multirow[b]{2}{*}{16,7} & 23,8 & 27,8 \\
\hline & $\begin{array}{l}\text { JPV no convoca a los } \\
\mathrm{CV} \text {, no se comunica } \\
\text { bien con los CV. }\end{array}$ & & & & \multicolumn{2}{|c|}{$52 \%$} \\
\hline & \multirow{2}{*}{$\begin{array}{l}\text { 9. Entre las Mesas } \\
\text { Coordinadoras (JPV) } \\
\text { no hay diálogo }\end{array}$} & \multirow[t]{2}{*}{14,3} & \multirow[t]{2}{*}{7,1} & \multirow[t]{2}{*}{23} & 22 & 33,3 \\
\hline & & & & & & $5 \%$ \\
\hline & $\begin{array}{l}\text { 11. Hay que hacer } \\
\text { que desde los barrios }\end{array}$ & & & & 19 & 63,5 \\
\hline & $\begin{array}{l}\text { participe más gente } \\
\text { en PP y JPV, porque } \\
\text { si somos solo } \\
\text { nosotros estamos en } \\
\text { problemas. }\end{array}$ & 8,7 & 4 & 4,8 & &, $5 \%$ \\
\hline \multirow{2}{*}{ 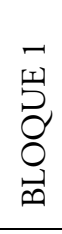 } & \multirow{2}{*}{$\begin{array}{l}13 . \\
\text { funcionamiento de } \\
\text { las JPV y PP depende } \\
\text { de la continuidad de } \\
\text { sus miembros }\end{array}$} & \multirow[b]{2}{*}{8,6} & \multirow[b]{2}{*}{6,3} & \multirow[b]{2}{*}{14,8} & 21,1 & 49,2 \\
\hline & & & & & \multicolumn{2}{|c|}{$70 \%$} \\
\hline \multirow{6}{*}{ 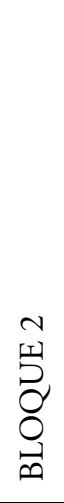 } & $\begin{array}{l}2 . \quad \text { La gestión } \\
\text { municipal no cumple }\end{array}$ & \multirow[b]{2}{*}{16} & \multirow[b]{2}{*}{4,2} & \multirow[b]{2}{*}{17,6} & 21 & 41,2 \\
\hline & $\begin{array}{l}\text { municipal no cumple } \\
\text { con el \% del } \\
\text { presupuesto para el } \\
\text { PP. }\end{array}$ & & & & & $2 \%$ \\
\hline & \multirow{2}{*}{$\begin{array}{l}\text { 5. Los empleados y } \\
\text { funcionarios del área } \\
\text { (JPV-PP) no están } \\
\text { capacitados. }\end{array}$} & \multirow[b]{2}{*}{19,2} & \multirow[b]{2}{*}{8} & \multirow[b]{2}{*}{19,2} & 21,6 & 32 \\
\hline & & & & & & $4 \%$ \\
\hline & \multirow{2}{*}{$\begin{array}{l}\text { 6. Los funcionarios } \\
\text { del área no duran }\end{array}$} & \multirow{2}{*}{19,4} & \multirow{2}{*}{8,1} & \multirow{2}{*}{14,5} & 31,5 & 26,6 \\
\hline & & & & & \multicolumn{2}{|c|}{$58 \%$} \\
\hline
\end{tabular}




\begin{tabular}{|c|c|c|c|c|c|c|}
\hline & $\begin{array}{l}\text { mucho en sus cargos } \\
\text { afectando la gestión. }\end{array}$ & & & & & \\
\hline & \multirow{2}{*}{$\begin{array}{l}\text { 10. En las JPV las } \\
\text { acciones } \\
\text { limitadas al PP }\end{array}$} & \multirow[b]{2}{*}{16,9} & \multirow[b]{2}{*}{4,8} & \multirow[b]{2}{*}{16,1} & 21 & 41 \\
\hline & & & & & \multicolumn{2}{|c|}{$62 \%$} \\
\hline \multirow[b]{4}{*}{ 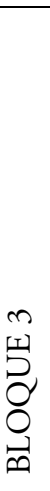 } & \multirow{2}{*}{$\begin{array}{l}\text { 3. La ordenanza del } \\
\text { PP nos permite } \\
\text { participar } \\
\text { ampliamente, } \\
\text { debemos saber cómo } \\
\text { usarla }\end{array}$} & \multirow[b]{2}{*}{4,9} & \multirow[b]{2}{*}{4,9} & \multirow[b]{2}{*}{9,8} & 26 & 54,5 \\
\hline & & & & & \multicolumn{2}{|c|}{$80,5 \%$} \\
\hline & \multirow{2}{*}{ 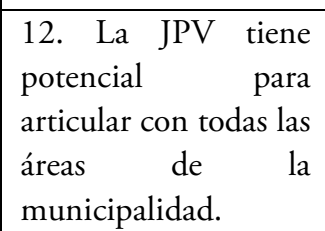 } & \multirow[b]{2}{*}{6,3} & \multirow[b]{2}{*}{4,7} & \multirow[b]{2}{*}{14,8} & 16,4 & 57,8 \\
\hline & & & & & & \\
\hline & 4. Se realizan obras & & & & 19,4 & 45,2 \\
\hline & $\begin{array}{l}\text { por fuera del circuito } \\
\text { o incumbencia de las } \\
\text { JPV y PP, inclusive } \\
\text { desconociendo las } \\
\text { decisiones de esos } \\
\text { espacios. }\end{array}$ & 11,3 & 6,5 & 17,7 & & \\
\hline & 7. La falta de & & & & 33,1 & 37 \\
\hline 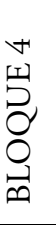 & $\begin{array}{l}\text { credibilidad en los } \\
\mathrm{CV} \text {, lleva a los } \\
\text { vecinos a gestionar } \\
\text { directamente ante el } \\
\text { municipio }\end{array}$ & 12,6 & 7,9 & 9,4 & & \\
\hline
\end{tabular}

Fuente: Elaboración propia. 
Tabla 2 - Perspectiva de la ciudadanía de Villa María sobre PP, CV y CB: porcentajes (N=60)

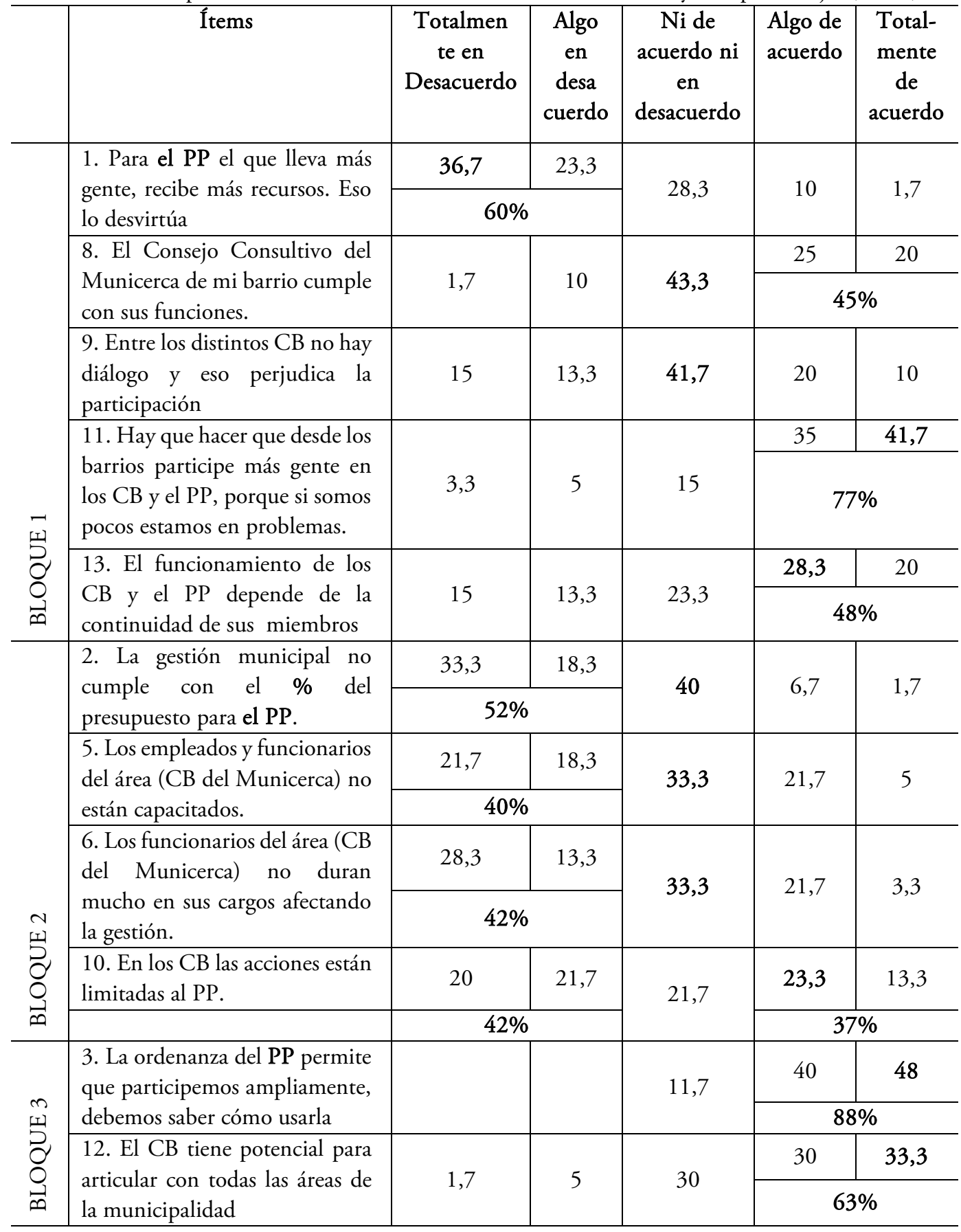




\begin{tabular}{|c|c|c|c|c|c|c|}
\hline \multirow{4}{*}{ 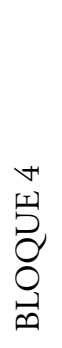 } & \multirow{2}{*}{$\begin{array}{l}\text { 4. Se realizan obras por fuera del } \\
\text { circuito o incumbencia del PP, } \\
\text { inclusive desconociendo las } \\
\text { decisiones de ese espacio. }\end{array}$} & 18,3 & 10 & \multirow{2}{*}{40} & 23,3 & 8,3 \\
\hline & & \multicolumn{2}{|c|}{$28 \%$} & & \multicolumn{2}{|c|}{$32 \%$} \\
\hline & \multirow{2}{*}{$\begin{array}{l}\text { 7. La falta de credibilidad en los } \\
\mathrm{CV} \text {, lleva a los vecinos a } \\
\text { gestionar directamente ante el } \\
\text { municipio }\end{array}$} & \multirow[b]{2}{*}{13,3} & \multirow[b]{2}{*}{15} & \multirow[b]{2}{*}{26,7} & 25 & 20 \\
\hline & & & & & \multicolumn{2}{|c|}{$45 \%$} \\
\hline
\end{tabular}

Fuente: Elaboración propia.

Al considerar el primer bloque de ítems se observa una diferencia entre ambas ciudadanías. Para los/as participantes de Córdoba el desajuste de esta institucionalidad es mayor (ítems 1, 8 y 9), reconociendo que las propias prácticas desvirtúan el proceso que debiera darse para garantizar procesos y decisiones justas obstaculizando la acción política de sus pares. Sí coinciden en que es necesaria una mayor participación por parte de la ciudadanía para evitar que esta institucionalidad tenga problemas (ítem 11), lo cual indica cuál es la expectativa respecto del patrón de comportamiento requerido para su funcionamiento pleno, a la vez que informa sobre el desajuste actual respecto de dicho patrón.

En función del segundo bloque de ítems, los cuales refieren a dimensiones de análisis recuperadas de los antecedentes, observamos que las experiencias también difieren. En Córdoba el desajuste vuelve a ser mayor y da cuenta de la discrecionalidad de la autoridad local para desvirtuar el proceso previsto (ítem 10) y obstruir la concreción de las decisiones tomadas (ítem 2). Cabe resaltar que llama la atención el porcentaje de respuestas "Ni-Ni" entre los/as participantes de Villa María.

El tercer bloque registra una similar valoración de las normativas de ambas ciudades, enfatizando el potencial que tienen para garantizar la participación, tanto la restringida al PP (ítem 3) como la más amplia y orientada hacia las políticas públicas locales (ítem 12).

El último bloque permite reconocer tanto una diferencia como una similitud entre ambas experiencias. $\mathrm{Al}$ considerar el ítem 4, el desajuste en términos de proceso y de decisiones justas es más marcado en Córdoba, implicando el accionar de los/as propios/as participantes en dicho desajuste. En cambio respecto del ítem 7, registramos que la expectativa ante los CV es similar y justifica así la desviación respecto del patrón de comportamiento requerido por la institucionalidad local. 


\section{Proceso participativo en torno a politicas culturales locales en Córdoba}

Se llevó a cabo un estudio de tipo cualitativo. Se analizaron dos entrevistas en profundidad con participantes de la sociedad civil en el Concejo (realizadas en 2017 y 2020), comunicaciones personales con una funcionaria de la Dirección de Cultura Viva (ex Dirección de Cultura Comunitaria) y fuentes secundarias (Ordenanzas 12500 y 12957 y textos producidos por funcionarios municipales sobre los procesos participativos) (IBERCULTURA VIVA, 2020).

Al proceso participativo por el Programa de Fortalecimiento a los Festejos Comunitarios de Carnaval se articularon agrupaciones que desde 2012 demandaban la agilización de las habilitaciones para estas expresiones culturales que tienen lugar en territorios sub-municipales. El proceso fue impulsado principalmente por "organizaciones de carnaval" acompańadas por la Universidad Nacional de Córdoba y la Secretaría de Cultura. Inicialmente se intentaba contemplar a todas las manifestaciones artísticas-culturales que se desarrollaran en la vía pública. Esto no se logró pues algunos colectivos carecían de organización y de interés en dialogar con el Estado municipal (debido a diferencias políticas con el partido oficialista). Producto de ese proceso de incidencia en 2015 se aprueba el Programa (Ordenanza 12500) que garantiza a los beneficiarios una serie de mejoras infraestructurales y administrativas para llevar adelante sus propuestas artísticas en los territorios.

Para la Ordenanza de Cultura Comunitaria el proceso fue similar. Algunos actores de la sociedad civil y funcionarios de la Secretaría de Cultura participaron en ambos de manera protagónica y sostenida. Se contó con el trabajo y los recursos organizativos de colectivos que ya estaban movilizados desde 2013 por la Cultura Viva Comunitaria demandando políticas culturales al Estado en sus tres niveles.

Respecto de las oportunidades percibidas por los participantes movilizados, vale decir que las organizaciones aprovecharon el contexto para abrirse camino mediante sus procesos de incidencia y propuestas de trabajo conjunto con un área de gobierno que se mostró receptiva ${ }^{3}$. Sin embargo, los desajustes percibidos se asocian a la fuerte dependencia de la voluntad de quienes ocupan los cargos políticos en las carteras de cultura. En ese sentido, por ejemplo, la continuidad por dos gestiones municipales de la misma persona a cargo de la Dirección de Cultura Comunitaria, permitió acumular

\footnotetext{
${ }^{3}$ Subsecretaría de Culturas y Descentralización (2011-2015), luego Dirección de Cultura Comunitaria, y actualmente Dirección de Cultura Viva.
} 
experticia y sostener los canales de diálogo, a pesar del cambio de gestión em el gobierno.

En términos generales la participación en la toma de decisiones del programa Cultura de Barrio pudo satisfacer medianamente la "necesidad de justicia procesal y autodeterminación”, al contemplar aportes para la redacción de la Ordenanza de Promoción de la Cultura Comunitaria, lo que ha motivado a las personas involucradas a continuar activas. Ese ajuste social, sin embargo, ha sido parcial. Por un lado, fue percibida como positiva la incorporación en el texto de la Ordenanza de una instancia que ya estaba funcionando de hecho (Consejo Municipal de Cultura Comunitaria), a los fines de democratizar el debate por las definiciones de política cultural. Por el otro, el desajuste social de ese órgano de participación refiere a la falta de reglamentación de la elección de representantes, el período de renovación de los mismos y la procedencia sectorial. Una entrevistada explicita que una "primera constitución" se hizo seleccionando "a dedo" a los integrantes, dando cuenta del desajuste percibido respecto de un proceso que se espera garantice una conformación que sea realmente representativa.

Esto limita las potencialidades percibidas en torno a la ampliación de la participación que este Consejo propiciaría, además de las vinculaciones posibles con Programas y políticas de otros niveles del Estado y otros institutos culturales locales. Más aún cuando desde la perspectiva de un entrevistado se reconoce que es necesaria una mayor inclusión, convocando a "otras organizaciones de cultura comunitaria que no se identifican como tales y hace mucho tiempo que están haciendo trabajo en el territorio".

\section{Discusiones}

La afectación de cada vez más dimensiones de la vida por parte del Estado es un hecho y en ese proceso se registra, a su vez, un aumento y pluralización de las modalidades participativas, en un intento por instaurar una mayor apertura dentro de un sistema que sigue concentrando el poder decisional en los representantes. Así el vínculo entre el sistema representativo y una institucionalidad que contempla dimensiones no electorales dentro de un gobierno local es relevante para valorar cuán democratizante pueden resultar los órganos y procesos políticos relativos a dichas dimensiones. 
Respecto de dichos órganos, en Córdoba ya se ha reportado que quienes se vinculan con las JPV y el PP suelen tener participación previa y simultánea en partidos políticos y/o CV (SORRIBAS, EBERHARDT y GUTIÉRREZ, 2016). Respecto de Villa María, cabe resaltar que el presente estudio se basó en una muestra donde un 45\% de los participantes activos en los CB y el PP desempeñaba actividades laborales dentro del municipio y un $37 \%$ estaba vinculado a un partido político. Esto indica una cierta imbricación y una ampliación de la participación dentro de la sociedad política (ROMÃO, 2011). Ampliación que también puede ser considerada como reforzamiento de la estructura de poder instaurada por el sistema representativo mediante la vía participativa prevista para la ciudadanía. Este reforzamiento también está dado por la colonización de estos espacios producida por la introducción de estrategias propias de la arena electoral (conseguir más votantes en las instancias críticas del PP) al interior de una institucionalidad más orientada a la deliberación y toma de decisiones basadas en argumentaciones.

En función de los resultados registrados en torno al accionar de funcionarios/ representantes frente a esta institucionalidad, se puede sostener que persiste el poder de definir no sólo quiénes, cómo y cuándo participan sino también para qué participan. $\mathrm{Al}$ menos desde la perspectiva de quienes cuentan con alguna experiencia participativa, estas autoridades del sistema técnico-político también pueden limitar o constreñir esta institucionalidad (SANTOS et al., 2018), reduciendo el campo decisional de las JPV y los $\mathrm{CB}$ a las decisiones específicas y más acotadas del PP. Por ende, se produce una rereducción de la esfera política (IGLESIAS ALONSO, 2009), dentro de una esfera ya reducida.

De modo similar a lo establecido por Gomes Dau et al. (2019), los resultados obtenidos permiten reconocer un patrón comportamental que tiende a la no participación más allá de la dimensión electoral y una debilidad relativa al perfil de funcionarios/representantes que tienen a su cargo las áreas de las que dependen estas instancias participativas, principalmente en el caso de Córdoba.

La percepción de desajuste por parte de los/as participantes refiere tanto al aspecto cuantitativo de la participación ciudadana, como al cualitativo en el sentido de continuidad del involucramiento con instancias exigentes en términos de intensidad y diversidad de roles y habilidades (procesar información técnica y conocimiento vulgar, socializar opiniones sobre diferentes temas; debatir y reflexionar sobre argumentos para establecer prioridades; lograr acuerdos sobre diagnósticos -problemas; deliberar sobre propuestas de obras y servicios que estén en la agenda gubernamental; valorar y elegir 
las personas más idóneas para realizar funciones de delegados, entre otras). La experticia para desempeńarse como ciudadano participativo en el marco de estas modalidades no está dada; se desarrolla experimentando con ellas. Para ello la permanencia es indispensable, sólo así se podría lograr que estos órganos sean habilitantes (FISHKIN, 2018) y eviten el soft-paternalismo (COLANDER y QUI LIN CHONG, 2009) por parte de las autoridades y una participación light (SANTOS et al., 2018) desde las prácticas de la ciudadanía.

Por su parte, los procesos políticos en torno de las políticas culturales en Córdoba continúan en una senda principalmente difusionista. En muchos casos, esto conlleva una idea de descentralización de actividades y propuestas artístico-culturales entendida como un indicador de ampliación de la participación al producir cultura. Al contrastar con los antecedentes de Villa María se observa que también en Córdoba persiste el sentido de democratización homologado al acceso a bienes, más que a participación en la toma de decisiones sobre las políticas. Sin embargo en Córdoba, algunos procesos de trabajo colaborativos dieron lugar a programas y legislación con participación de actores colectivos: la adopción desde el Ejecutivo Municipal de criterios y definiciones de los propios actores civiles, asociados al sector de la Cultura Comunitaria, contando desde 2015 con un área específica. Sin embargo, ha sido crucial el sostenimiento de la participación y los recursos organizativos de colectivos y personas con suficiente interés, trayectoria y contactos territoriales, así como la permanencia en los cargos de determinados funcionarios que fueron acumulando experticia.

\section{Conclusiones}

De acuerdo a las voces críticas recuperadas en los antecedentes, la institucionalidad analizada desde la perspectiva de los actores participativos evidencia algunas resonancias con ellas. Principalmente, la fortaleza del sistema representativo por sobre las instancias que intentan abrirlo y ampliar el campo decisional de la ciudadanía. Fortaleza que -en el caso de la provincia de Córdoba- deriva de un diseño institucional que desvirtúa al mismo sistema representativo por el funcionamiento de la cláusula de gobernabilidad ${ }^{4}$ que crea grandes disparidades de escaños/votos en el Concejo Deliberante, incrementando el poder y la discrecionalidad de fuerzas políticas que no logran constituirse en mayorías electorales en ambas ciudades. La robustez del

\footnotetext{
${ }^{4}$ Según esta cláusula la fuerza política que obtenga más votos para Intendente y Vice-Intendente aunque no alcance la mayoría (51\%), obtiene la mayoría automática de los Concejales.
} 
poder de los representantes también deriva de la limitada apertura del campo decisional correspondiente a la institucionalidad participativa local tanto en relación con los asuntos sobre los cuales se convida a la participación ciudadana, como por la escala de las decisiones, generalmente circunscrita a territorios sub-municipales o barriales. A la par, desde la misma apertura participativa se posibilita el reforzamiento de actores vinculados a partidos políticos, dinámicas electorales o a la gestión municipal como sucede de modo más marcado en Villa María debido al vínculo laboral de los/as participantes. Y por último es de destacar la subordinación de las instancias participativas al poder sustentado por los ejecutivos locales, quienes tienen la atribución de activarlas, desactivarlas, suspenderlas o inclusive de hacer que funcionen de modo desigual dentro del mismo territorio municipal mejorando la calidad de la democracia sólo en algunos sectores (IGLESIAS ALONSO, 2009; SORRIBAS, EBERHARDT y GUTIÉRREZ, 2016).

En función de esta constatación podemos sostener que a nivel macro, la estructura de poder está muy lejos de la influencia de estos entornos participativos, pues no se vinculan con cambios más amplios (SINTOMER, 2018) que -cuando emergen y se configuran como opciones- derivan de otros procesos políticos. Más aún y en sintonía con Santos, Batel y Gonçalves (2018) podemos inclinarnos a afirmar que tal como funcionan, estas instituciones más bien reproducen las tradicionales relaciones de poder entre los sistemas técnico-políticos y una ciudadanía que en parte reproduce prácticas partidarias-electorales.

En complementariedad con esta evidencia, reconocimos desde la perspectivas de los/as propios/as participantes diversas dimensiones del funcionamiento concreto de la institucionalidad local. Es decir, el mismo reforzamiento del sistema representativo debido al accionar de la ciudadanía, de los funcionarios/representantes y de la combinación de ambos es reconocido como parte del desajuste que caracteriza a estos canales institucionalizados. En ambas ciudades se registran indicadores de desajuste social, debilitando la aceptación institucional, siendo mayor en el caso de Córdoba. Estos resultados pueden corresponderse con una interpretación cognitiva y cultural del contexto político como no cambiante (CARLOS, 2015) a pesar de la innovación institucional.

En el campo específico de las políticas culturales, el desajuste social es parcial debido a que la valoración general fue que los procesos reforzaban la autodeterminación de los colectivos redundando en una buena aceptación institucional. Sin embargo, la democratización en la toma de decisiones de políticas públicas culturales resultó 
desigualmente distribuida. La apertura sólo pudo ser percibida como una oportunidad por actores que contaban con trayectoria, capacidad organizativa y conocimientos relacionados con las innovaciones producidas en materia de política cultural a nivel nacional. El Consejo Municipal de Cultura Comunitaria se constituyó en un órgano activo de hecho mientras duró el proceso participativo de elaboración de la Ordenanza vinculada al propio sector. Esa experiencia y otras similares, generaron conocimiento experto tanto en actores colectivos como en funcionarios que continuaron en sus cargos. El desajuste social se produce a causa de las limitaciones de la normativa y las prácticas discrecionales de autoridades, lo que es percibido como una falencia en la democratización de la institucionalidad participativa y un límite a sus potencialidades para articularse con diferentes sectores.

La aproximación realizada aquí contribuye a sostener el desafío de diseñar una institucionalidad que por su escala y amplitud del campo decisional permita afrontar las deudas de la democracia en la región latinoamericana, democratizando la participación. Compartimos las palabras de Sintomer (2018, p. 162) sobre el viraje que debería producirse: "los cambios reales implicarán iniciativas ascendentes". De acuerdo a este autor se torna necesario un nuevo tipo de gobierno mixto que integre tanto a actores tradicionales (legisladores) como a la ciudadanía y que ésta actúe en entornos más deliberativos y en instancias de voto orientadas a la toma de decisiones (consultas o referéndums). Un nuevo [co] gobierno que solo sería viable y materializable en un futuro previsible si en su diseño e implementación integrara "el hecho sociológico de la asimetría de poder" (SINTOMER, 2018, p. 162); cuestión que hasta ahora no ha sido considerada a pesar de la retórica participacionista y que aumenta los riesgos de retrocesos democráticos ante la emergencia de actores políticos-partidarios autoritarios o con tendencias hacia la concentración de poder decisional.

Patricia Mariel Sorribas é Investigadora no IIPSI-CONICET, Professora Assistente na Universidad Nacional de Córdoba e Coordenadora Geral do Grupo Democracia Local (Rede Ciudadana Nuestra Córdoba). Doutora em Psicologia pela Universidade Nacional de Cordoba. E-mail: patricia.sorribas@conicet.gov.ar.

Mariana Carla Gutierrez é Mestra em Sociologia pela Universidade Nacional de Cordoba. Doutoranda pela Universidade Nacional de Córdoba. É Bolsista cofinanciada pelo CONICET e UNC, com lugar 


\section{de trabalho no IECET (CONICET-UNC). E-mail para contato: marucgutierrez@gmail.com.}

\section{Referências}

ALLEGRETTI, Giovanni y HERZBERG, Carsten. El retorno de las carabelas: los presupuestos participativos de Latinoamérica en el contexto europeo. Web Delegación participación Ciudadana del Ayuntamiento de Sevilla, 2004.2 Disponível http://www.sevilla.org/html/portal/com/bin/contenidos/participacionCiudadanaDistritos/presupuest os_participativos/biblioteca_documentos/retorno_carabelas/1140437577264_bb_alegretti.pdf.

Acesso em: $10 \mathrm{dez} .2019$.

ARGENTINA, Resolución 190/2016. Boletín Oficial Nacional-Argentina. Disponível em: https://www.argentina.gob.ar/normativa/nacional/resoluci\%C3\%B3n-190-2016-261744. Acesso em: 10 dez. 2019.

AVRITZER, Leonardo. A qualidade da democracia e a questão da efetividade da participação: mapeando o debate. In: ROCHA PIRES, Roberto. (Org.). Efetividade das instituiçóes participativas no Brasil: estratégias de avaliação. Brasília: IPEA, v. 7, 2011, p. 14-370.

AVRITZER, Leonardo. Participatory Institutions in Democratic Brazil. Washington/Baltimore: Woodrow Wilson Center/Johns Hopkins University Press, 2008.

BARABAS, Jason. How Deliberation Affects Policy Opinions. American Political Science Review, v. 98, n. 4, p. 687-701, 2004.

BAYARDO, Rubens. Políticas culturales: derroteros y perspectivas contemporáneas. Revista de Investigaciones Políticas y Sociológicas, v. 7, n. 1, p. 17-30, 2008. Disponível em: https://www.redalyc.org/pdf/380/38070103.pdf. Acesso em: 16, dic., 2020.

CARLOS, Euzeneia. Movimentos sociais e Instituiçôes Participativas. efeitos do engajamento institucional no contexto pós-transição. Belo Horizonte: Fino Traço, 2015.

CHAUI, Marilena. Ciudadania cultural. El derecho a la cultura, Buenos Aires: RGC Libros, 2013.

COLANDER, David; QUI LIN CHONG, Andrew. The Choice Architecture of Choice Architecture: Toward a Nonpaternalistic Nudge Policy. Discussion Paper n. 10-36, Middlebury College Economics. Vermont: Middlebury College, 2009.

DAGNINO, Evelina. Confluencia perversa, desplazamiento de sentido, crisis discursiva. In: BRINGEL, Breno; BRASIL, Antonio Jr. (org.). Antología del pensamiento crítico brasileño contemporáneo. Buenos Aires: CLACSO, 2018, p. 679-700.

DECARO, Daniel; STOKES, Michael. Public participation and institutional fit: a socialpsychologicalperspective. Ecology and Society, v. 18, n. 4, p. 40-62, 2013. Disponível em: http://dx.doi.org/10.5751/ES-05837-180440. Acesso em: 10 dez. 2020. 
ECHAVARRÍA, Corina y ROMANUTTI, Virgina. La factibilidad de la deliberación sobre los recursos públicos: diseños institucionales y prácticas de la ciudadanía en la ciudad de Córdoba. Más Poder Local, v. 20, p. 42-53, 2014. Disponível em: http://hdl.handle.net/11086/5967. Acesso em: 10 dez. 2020.

FISHKIN, James. Democracy When the People Are Thinking: Revitalizing Our Politics Through Public Deliberation. Oxford: Oxford University Press, 2018.

GOMES DAU, Arthur; PREZOTTI PALASSI, Márcia; ZORZAL E SILVA Marta. Consciência política e participação dos representantes da sociedade civil no Conselho Municipal de Assistência Social de Vitória - ES. Cadernos EBAPE.BR, v. 7, n. 1, p. 199-211, 2019. Disponível em: http://dx.doi.org/10.1590/1679-395169859. Acesso em: 25 nov. 2020.

GUTIÉRREZ, Mariana; SORRIBAS, Patricia. Acciones colectivas y políticas culturales de base comunitaria: Resonancias, incidencia y gestión compartida en Puntos de Cultura (2011-2019). Cartografías del Sur, v.1, n. 12, p. 252-285, dic. 2020. Disponível em: https://cartografiasdelsur.undav.edu.ar/index.php/CdS/article/view/198/168. Acesso em: 31 dez. 2020.

GUTIÉRREZ, Mariana. La “Cultura Comunitaria” como práctica y como política pública: Un Análisis desde la perspectiva de actores colectivos e institucionales. 2019. 127f. Tese (Mestrado em Sociologia). Centro de Estudios Avanzados. Universidad Nacional de Córdoba, Córdoba, 2019.

IBERCULTURA VIVA. Red de ciudades y gobiernos locales. Disponível em: https://iberculturaviva.org/red-de-ciudades-y-gobiernos-locales/?lang=es. Acesso em: 21 dez. 2020.

IGLESIAS ALONSO, Angel. E-participation and local governance: A case study. Theoretical and Empirical Researches in Urban Management, v. 3, n. 12, p. 49-62, 2009. Disponível em: https://core.ac.uk/download/pdf/6421637.pdf2009. Acesso em: 23 ago 2020.

ISUNZA VERA, Ernesto; GURZA LAVALLE Adrián. Arquitetura da participação e controles democráticos no Brasil e no México. Novos estud. - CEBRAP, n. 92, p. 105-121, 2012. Disponível em: https://www.scielo.br/scielo.php?script=sci_arttext\&pid=S0101-33002012000100007. Acesso em: 11 dez 2020.

LEIRAS, Marcelo. La incidencia de las organizaciones de la sociedad civil en las políticas públicas. Definiciones, explicaciones y evaluaciones de la literatura especializada local e internacional. In: ACUÑA, Carlos; VACCHIERI, Ariana (org.). La incidencia política de la sociedad civil. Buenos Aires: Siglo XXI, 2007, p. 17- 66.

LISSIDINI, Alicia. Democracia directa en Latinoamérica: entre la delegación y la participación. Buenos Aires: CLACSO, 2011.

MANIN, Bernard; STEIN, Elly; MANSBRIDGE, Jane. On legitimacy and political deliberation. Political Theory, v. 15, n. 3, p. 338-368, 1987.

MENDES CALADO, Pablo. Las políticas culturales de los gobiernos locales en la Argentina. Rev. pueblos front. digit., v. 7, n. 13, p. 127-146, jun. 2012. Disponível em: http://www.scielo.org.mx/scielo.php?script=sci_arttext\&pid=S1870-

$41152012000100005 \& \operatorname{lng}=$ es\&nrm=iso. Acesso em: $11 \mathrm{dez} 2020$.

MENDES CALADO, Pablo. Políticas Culturales: Rumbo y deriva. Caseros: RGC libro, 2015. 
MERCADAL, Silvia. Creación y sociedad: la gestión cultural pública en Villa María. Córdoba: Lago Editora, 2020.

MONTALI, Gabriel. Políticas culturales: debates en torno al poder y los procesos de democratización In: MERCADAL, Silvia (org.). Creación y sociedad: la gestión cultural pública en Villa María. Córdoba: Lago Editora, 2020. p. 75-96.

MUNICIPALIDAD DE CÓRDOBA. Ordenanza No 12500/2015. Disponível em: https://servicios2.cordoba.gov.ar/DigestoWeb/Page/Documento.aspx?Nro=55469. Acesso em: 10 dez. 2019.

MUNICIPALIDAD DE CÓRDOBA. Ordenanza No 12975/2019. Disponível em: https://iberculturaviva.org/wp-content/uploads/2019/04/ordenanza-cultura-viva-comunitaria-1.pdf. Acesso em: 10 dez. 2019.

MUNICIPALIDAD DE CORDOBA. Ley No 8102 (1995). Regimen de Municipios y comunas, La Carta Orgánica, Cordoba, Argentina, 1995. Disponível em: http://mininterior.gov.ar/municipios/pdf/ley-organica-cordoba.pdf. Acesso em: 10 dez. 2019.

OSZLAK, Oscar; KAUFMAN, Ester (org.). Teoría y práctica del gobierno abierto: Lecciones de la experiencia internacional. Buenos Aires: OEA, Red Gealc e IDRC, 2014.

OSZLAK, Oscar. Gobierno abierto: Hacia un nuevo paradigma de gestión pública. In: OSZLAK, Oscar; KAUFMAN, Ester (org.). Teoría y práctica del gobierno abierto: Lecciones de la experiencia internacional. Buenos Aires: OEA, Red Gealc e IDRC, 2014, p. 5-58.

PARÉS I FRANZI, Marc. Participación y evaluación de la participación. In: PARÉS I FRANZI, Marc (org.). Participación y calidad democrática evaluando las nuevas formas de democracia participativa. Barcelona: Ariel, 2009, p. 15-28.

PERUZZOTTI, Enrique; SMULOVITZ, Catalina. Accountability social: la otra cara del control. In: PERUZZOTTI, Enrique; SMULOVITZ, Catalina (org.). Controlando la política. Ciudadanos y medios en las democracias latinoamericanas. Buenos Aires: Temas, 2002, p. 1-38.

RAMÍREZ ALUJAS, Álvaro V.; DASSEN, Nicolás. Gobierno abierto: la ruta hacia una nueva agenda de reforma del Estado y modernización de la administración pública en América Latina y el Caribe. In: DASSEN, Nicolás ; VIEYRA, Juan Cruz (org.). Gobierno abierto y transparencia focalizada: tendencias y desafíos para América Latina y el Caribe. Washington: BID, 2012, p. 41-71.

ROMÃO, Wagner de Melo. Conselheiros do Orçamento Participativo nas franjas da sociedade política. Lua Nova, n. 84, p. 219-244, 2011. Disponível em: http://www.scielo.br/scielo.php?script=sci_arttext\&pid=S010264452011000300008\&lng=en\&nrm=iso. Acesso em: 10 dez. 2020.

ROMÃO, Wagner de Melo. Partidos políticos y democracia participativa: estatus político y perfil asociativo en los presupuestos participativos de Brasil. Revista Española de Ciencia Política, n. 42, p. 69-96, nov. 2016. Disponível em: https://recyt.fecyt.es/index.php/recp/article/view/50627/pdf_47. Acesso em: 10 dez 2020.

SABUCEDO, José M. Participación política. En: SABUCEDO, José. M. (org.). Psicología Política. Madrid: Síntesis, 1996, p. 85- 97.

SÁNCHEZ GONZÁLEZ, José J. El Gobierno Abierto en México: las dificultades para su implementación en los niveles subnacional y local. Estado abierto, v. 4, n. 2, p. 13, 2020. 
SANTOS, Margarida; BATEL, Susana; GONÇALVES, Maria Eduarda. Participar está na moda: uma abordagem psicossocial dos orçamentos participativos. Psicologia \& Sociedade, n. 30, p. 1-11, 2018. Disponible en: http://dx.doi.org/10.1590/1807-0310/2018v30165726 Acesso em: 23 ago 2020.

SINTOMER, Yves. Deliberative Polls and the Systemic Democratization of Democracy. The good society, v. 27, n. 1-2, p. 155-164, 2018.

SINTOMER, Yves; HERZBERG, Carsten; RÖCKE, Anja. Les budgets participatifs en Europe. Des services publics au service du public. París: La Découverte, Recherches, 2008.

SORRIBAS, Patricia; GARAY REYNA, Zenaida. La participación, entre la democracia participativa y la democracia directa: Aportes desde un enfoque psicosocial. Polis, v. 10, n. 2, p. 39-69, 2014.

SORRIBAS, Patricia. Las instituciones locales de democracia participativa en Córdoba: análisis del perfil de sus participantes. Revista Latinoamericana de Opinión Pública, n. 7, p. 185-204, 2017.

SORRIBAS, Patricia; EBERHARDT, Laura; GUTIÉRREZ, Mariana. Instituciones de democracia participativa en Córdoba. Una aproximación al análisis del tipo de organizaciones sociales participantes y sus vínculos con partidos políticos. XII Congreso Nacional y V Congreso Internacional sobre Democracia. Rosario, 2016.

SORRIBAS, Patricia; GUTIÉRREZ, Mariana; GARAY REYNA, Zenaida; MALDONADO, Ivana. Entorno político institucional en Córdoba y contexto COVID19: (im)permeabilidad a los procesos de incidencia política ciudadana. In: GODY, Juan Carlos; PAZ GARCÍA, Pamela (org.): Salud Mental, Pandemia y Políticas Públicas. ISBN: 978-987-47803-1-7 (no prelo).

TASAT, José. Políticas Culturales de los gobiernos locales en el conurbano bonaerense. Indicadores Culturales 2008. Caseros: EDUNTREF, p. 185-191, 2009.

VALENCIA, Beatriz Siete años de Convenios Urbanisticos. Disponível em: https://www.nuestracordoba.org.ar/sites/default/files/SIETE\%20A\%C3\%91OS\%20DE\%20CONV ENIOS\%20URBANISTICOS.pdf 2019. Acesso em: 02 mar. 2021.

VAN DETH, Jan W. Studying political participation: Towards a theory of everything?. Joint Sessions of Workshops of the European Consortium for Political Research, Grenoble, p. 6-11, 2001.

VICH, Victor. Desculturizar la cultura. La gestión cultural como forma de acción política. Buenos Aires. Siglo XXI, 2014.

WARREN, Mark E. Governance-Driven Democratization. In: GRIGGS, Steven; NORVAL, Aletta; WAGENAAR, Hendrik (org.). Practices of Freedom: Democracy, Conflict and Participation in Decentred Governance. Cambridge: Cambridge University Press, 2014, p. 38-59.

Texto recebido em 31 de dezembro de 2020. Aprovado em 14 de abril de 2021. 